\title{
A Pragmatic Cross-Cultural Study of Complaints Expressions in Jordan and England
}

\author{
Nisreen Al-Khawaldeh \\ Department of English Language and Literature - The Hashemite University, P.O. Box 330127, Zarqa 13133, Jordan \\ E-mail: nal-khawaldeh@hu.edu.jo
}

Received: 10-04-2016

Accepted: 28-06-2016

Advance Access Published: July 2016

Published: 01-09-2016

doi:10.7575/aiac.ijalel.v.5n.5p.197

URL: http://dx.doi.org/10.7575/aiac.ijalel.v.5n.5p.197

\begin{abstract}
Research shows an increasing interest in the area of cross-cultural pragmatics due to the existence of diverse problematic pragmatic norms (Al-Khawaldeh and Zegarac, 2013). It has been found that identifying cross-cultural differences in linguistic expression and socio-pragmatic norms of communicative acts would help to reduce problems in cross-cultural communication (Meier, 2010). To the best of the researcher's knowledge, no study has been conducted to compare the linguistic expression of complaining by Jordanian native speakers of Arabic and native speakers of English. To bridge the research gap, this study compares the number and types of politeness strategies that Jordanian native speakers of Arabic and native speakers of English use to complain. The study investigates the cultural styles and politeness strategies used by Jordanian native speakers Arabic and native speakers of English for expressing complaints. The analysis of the Discourse-Completion Tasks' (DCT) results revealed that eleven complaints strategies were the most commonly-used by both groups, namely opting out, general annoyance, direct threat, accusation, prayer, advice, irony, rejoinder that shows no disapproval, exclamation, request for repair, and request for explanation. These strategies are manifested in the speech of both languages to save the hearer's face and remain polite when performing the inherently face-threatening speech act of complaint. Though both groups used various complaints strategies at overall frequencies that were closer, they were statistically distinguishable in the type of the linguistic expression of complaints, i.e. opting out and prayer. The results are then discussed from the universality and cultures-specificity perspective.
\end{abstract}

Keywords: Complaint, cross-cultural study, politeness, pragmatics, speech acts

\section{Introduction}

The importance of communicative competence has been widely asserted in the field of language teaching and learning. Language should be appropriately implemented to achieve the target communicative goals. This concept of "appropriateness" is achieved by mastering not only linguistic rules such as morphology, syntax, phonology and vocabulary, but also socio-cultural rules of language manifestation (Novick, 2000). Being cross-culturally competent means that speakers should be aware that though communicative acts appear to be universal, their conceptualization and verbalization may vary, to a great extent, cross-culturally (cf. Blum-Kulka, et al. 1989).Consequently, researchers (AlAmar, 2000; Al-Khawaldeh, 2013) warn that non-native speakers who are not pragmatically competent" run the risk of being misunderstood or misinterpreted as insulting, uncooperative, "rude" or even more serious. This promotes the notion of unwanted result of communication misinterpretation and communication breakdowns and communication (Scollon and Scollon, 1993). To avoid such miscommunications and their negative impact on human relations, more research should be conducted to highlight any cross-cultural differences in communication. In other words, pragmatics and communicative acts' appropriateness should be addressed more seriously.

\section{Literature review}

People often encounter uncomfortable situations which most of the time trigger their expression of complaints. The communicative expression of complaints has emerged most recently as a fruitful ground for cross-cultural comparative research being viewed as a signifier of cultural variation and one of the most multifaceted features of negotiation even between members of cultures which might be considered to share generally comparable traditions and norms (Crawshaw, et. al., 2010; Mayouf, 2013). Therefore, Spencer Oatey $(2003,2005)$ claims that it is not governed by universal pragmatic principles rather by both national and contextual convention.

Complaining, within speech act theory framework, is the speakers' communicative act to verbally expresses their annoyance, disagreement, disappointment, negative and unsatisfied feeling to a certain state of affairs, wrongdoing, speech, service, action, etc. (Austin, 1962; Searle, 1969).It is mainly addressed to the person whom the speaker believes to be responsible for his or her problem either directly or indirectly (Boxer, 1993; Trosborg, 1995, Tanck, 2002). Such moral judgment might be passed on something that the complainee has already done or failed to do, or is in the process of doing with some type of expected corrective actions or reaction to the complaint (Dersley and Wooton, 2000; 
Monzoni, 2009). It includes acts of threatening, accusing, cursing and reprimanding (Leech, 1981). Thus, it is intended to cause an offence that is highly threatening to the social relationship between the interlocutors.

The degree of directness is determined by the extent to which the complainer wants to explicitly mention the complaints to the complainee. In other words, the direct complaint itself is never formulated in the utterance (Trosborg, 1995). Clyne (1994) differentiates between whinges (i.e. "long or repeated expression of discontent not necessarily intended to change or improve the unsatisfactory situation" (Clyne, 1994: 49) and direct complaints (i.e. A direct complaint involves an explicit or implicit accusation and at least one explicit or implicit directive (Clyne, 1994: 54). ) where in whinges the addressee is not primarily held responsible for the perceived offence (Boxer, 1993); instead, whinges serve as a release of negative emotion safely, instead of provoking action to redress the offence. This could imply that they might be used as to elicit others' sympathy, thus as a means to build rapport with others.

A further distinction of two types of complaints has been introduced by Searle (1975): expressive complaints where the speaker should seek sympathy or commiseration from hearer and directive complaints where speaker should issue a directive (i.e. an attempt to persuade hearer to do something to repair the damage. Olshtain and Weinbach (1988) describe some preconditions in which an expression of complaint may occur: The speaker accounts with "socially unacceptable act" (SUA)

-The speaker perceives the consequences of it as offensive.

-The hearer is regarded as responsible for the SUA.

-The speaker decides to express his/her displeasure.

Studies on the communicative behavior of complaining behavior were mono-cultural, cross-cultural and inter-language studies (Yarahmadi and Fathi, 2015; Hussein,and Al-Mofti, 2014; Orthaber and Marquez-Reiter, 2011;Farnia, Buchheit, and Bintisalim, 2010; Henry and Ho, 2010;Chen, 2009; Monzoni, 2009; Önalan, 2009; Ruusuvuori and Lindfors, 2009 ; LaForest, 2009;Prykarpatska, 2008; Yian, 2008; Umar, 2006, Eslami Rasekh and Fatahi, 2004;Oh, 2003, Boxer, 1993; Schaefer, 1982; Bonikowska, 1988; Drew \& Holt, 1988; Bayraktaroğlu, 1992). Within politeness theory framework, complaining is a face-threatening act to the hearer (Brown, \& Levinson, 1987). Making direct complaint, the speaker is more likely to threat the addressee's face, thus hurt his/her feelings and damage their relationship (Moon, 2001).Consequently, speakers may tend to employ various linguistic forms along with nonverbal signals so as to save the hearer's face and remain polite even when performing the inherently face-threatening (Sauer, 2000). As in the case of this study, cross-cultural studies on complaint determine how respondents from different cultures vary in their choice of the preferred strategies.

Trosborg (1995: 348), a reference linguistic work on complaining, points out that one can complain using various ways: a complainer may not explicitly complain by formulating an indirect complain to show his/her awareness of offence but without using clear mentioning the exact cause to evade a conflict when revealing discontent such as "it was working properly yesterday". A complainer may also express his/her annoyance or disapproval explicitly as result from certain case or situation in which the complainer implies that a complainee should take responsibility but he/she avoids explicitly stating that complainee as a guilty person such as "Oh! This will make me lose my job". Moreover, a complainer may also resort to either accuse the complainee of being in some ways connected with the offence such as "Were you coloring next to my sofa?" or blame the complainee for being guilty of the offence such as "You really are inconsiderate; you have done it again".

Olshtain and Weinbach (1993) in his study also identified various types of strategies for the act of complaining. First, the mitigated strategy where the speaker decides to avoid the act and not to show his/her feelings of displeasure or annoyance to sound more polite and give the impression that he/she cares for the hearer. Second, the indirect strategy is when the speaker opts to perform the act of complaining in off-records by giving the hint of inconvenience to gain certain payoffs.

\section{Statement of the problem}

The present study was driven by some insights from previous works. Speakers are required to have socio-cultural competence alongside linguistic competence in order to perform the communicative acts appropriately. Being pragmatically incompetent risk of the danger of being misinterpreted, misunderstood, or might even experience communication breakdown as a result of lack of language mastery of communicative acts of complaining (Thomas, 1983). Special attention should be paid to the expression of complaints due to the fact that it is a face-threatening act when the speaker violates the socio-cultural rule of speaking. People from different cultures have different beliefs, values and attitudes which influence the way they communicate and are perceived by others. People may tend to explicitly or implicitly follow these specific socio-cultural norms/rules as they may guide the interpretation of communicative acts. According to Wolfson (1981: 123), "speech acts differ cross-culturally not only in the way they are realized but also in their distribution, their frequency of occurrence, and in the functions they serve".

The decision to focus particularly on this speech act was made based on its sensitivity and frequency as a salient instance of negatively affective communicative acts in everyday life. Complaining is a relatively more intricate communicative act because of the lack of pre-determined forms and the negotiable interpretations. Olshtain and Weinbach (1993) claims that performing the communicative act of complaint can involve different realization patterns which may vary in line with their degree of severity on the addressee's face . 
If being viewed by native speakers as very difficult to execute, performing the speech act of complaining is of course very challenging for nonnative speakers. Thus, in order to find out the appropriate means of expressing complaining, the utterances of native speakers of the target language and culture should be studied first and social variables affecting them should be analyzed. This means that cross-cultural comparison-based data, as this study, is needed to form a baseline for further inter-language investigations of points of inter-cultural clashes.

Previous cross-cultural studies on the communicative acts show that compared to other communicative speech acts, little attraction has been paid to the expression of complaints in general. To the best of the present researcher's knowledge, there has been no attempt to compare the culture of Jordan with that of England in relation to linguistically communicating complaints.

\section{Significance of the study}

The present study is original in that it makes a contribution to the field of cross-cultural pragmatics by considering the linguistic expression of complaints in two markedly different cultures of Jordan and England, in a way which addresses some considerable research gaps in the previous research. The comparison of the patterns of the linguistic realization of the expression of complaints in these two cultures assist us to gain more fine-grained insights into the dissimilarities and/or resemblances in the linguistic behaviours and the conceptualisations of linguistic politeness associated with it in these target cultures. The cast of new light on the sociopragmatic and pragmalinguistic aspects of the communicative expression of complaints could reduce the risk of miscommunication in intercultural communication situations between Jordanians and English.

Thus, it is hoped that the study will provide a substantial contribution to knowledge through enriching the growing body of comparative cross-cultural research as such comparison can provide important insights into theoretical issues regarding the nature of communicative acts, the relation between their types and the common principles of human communication, the social implications conveyed by performance besides the relation between the culture-specific and the universal features of communicative acts types. Besides establishing descriptions of how native speakers perform verbally in day-to-day interactions, this research sheds lights on English native speakers' linguistic behaviour of refusal. Thus, the study could serve as baseline information for further inter-language research and in educational settings. The newly formulated code scheme is of a great significance and can be adopted for further Jordan, other Arabic speaking countries, or English based-comparative studies. In light of Tanck's (2002) recommendation that material for teaching pragmatics should be based on careful analysis of research findings, the study is anticipated to be of a valuable enrichment to the applied linguistics field. In particular, it is pertinent and applicable to teaching both languages to non- natives, it benefits teachers and administrators in updating their present curricula and instructional plans considering what is new in research.

\section{Methodology}

\subsection{Research questions and hypotheses}

1. Are there any differences in the expression of complaints between Jordanian native speakers of Arabic and native speakers of English in respect of the use of different numbers of strategy for making complaints?

2. Are there any differences in the expression of complaints between Jordanian native speakers of Arabic and native speakers of English in respect of the use of different types of strategy for making complaints?

Hypothesis

$\mathrm{H}_{0}$ 1.1: Jordanian native speakers of Arabic and native speakers of English do not significantly use different numbers of strategies when making complaints.

$\mathrm{H}_{0}$ 1.2: Jordanian native speakers of Arabic and native speakers of English do not significantly use different types of strategy for making complaints.

\subsection{Instruments}

This research study adopted DCT as the research instrument for collecting data. Qualitative approach is appropriate to meet the aims of the present study of investigating the pattern and frequency of the linguistic expression of complaints. Despite the fact that DCTs may not be completely dependable research instrument since they do not actually mirror accurately an individual's behavior in, and their associated perceptions of, natural exchanges, they afford researchers the chance to collect typical responses pertaining to examples of typical situations from members of specific cultural groups, enabling them to categorize responses in a way which shows how representative these rejoinders are of particular situations in specific cultures. Well-designed DCTs are considered valuable instruments for revealing participants' pragmalinguistic knowledge of linguistic forms (i.e. the strategies) as they shape the communicative speech acts' structure as they are in the speakers' minds besides revealing their perception and sociopragmatic knowledge of the contextual variables under which specific strategies are appropriate (Kasper and Rose, 2002). Given that this research study is cross-cultural comparative study, DCTs are reliable enough to collect data which is consistent with natural data, at least in the main patterns and formulas with low costs within a short period in a controlled context (where we can vary and control the social and situational variables). They may be sufficiently accurate for testing the hypotheses under investigation and enable drawing a generalisation of semantic formulas and strategies used by a sample of target populations of sufficient size. Observation was not found possible for the present study due to some limitations; time, financial, the impossibility of having a homogeneous 
sample representative of population, besides the fact that the covert method of observation is ethically unacceptable being viewed as a breach of peoples' privacy (Bryman, 1989).

\subsection{Sample of the study}

The sample consisted of 70 participants who were selected randomly. Statistical analysis using T-test has been conducted to roll out significant differences as stated by Cresswell (2009). T-test was used to find out the comparison as there were one variable with two levels (culture; English and Jordanian). The significant differences were rolled out based on the means and standard deviations when the result was equal or less than $(\mathrm{p}<.05)$. The respondents were relatively homogenous in terms of their cultural background (Jordanian native speakers of Arabic, British native speakers of English). They were all undergraduate students in Jordan and the United Kingdom from the scientific and Humanities branches excluding those majoring in English or Arabic, and cross-cultural studies. This is to reduce the impact of familiar with linguistic pragmatics on their responses.

\subsection{Research design and framework}

This research is empirical and has some theoretical insights regarding politeness and cross-cultural communication. The systematic collection of the data involved both groups responding to the same set of social scenarios. The study consists of both descriptive (i.e. frequencies and percentages) and inferential statistics as a basis for analyzing the data regarding the difference of the realization of the linguistics expression of complaint from a cross-cultural perspective. The independent variables (i.e. the social and contextual variables of social status, social familiarity, and degree of imposition) were identified. To ensure a successful comparison of both cultures in the expression of complaints, it is necessary to compare similar situations regarding the degree of imposition, interlocutors' social status, and familiarity (Brown and Levinson, 1987:15). The number and type of strategy were also identified as the dependent variables to decide whether the differences between both groups are statistically significant. This necessitates classifying the complaints utterances used by speakers of the two languages in addition to identifying their semantic formulas used.

Theoretically, the present study is situated within (im) politeness research. Locher and Watts' relational work (2005), Spencer-Oatey (2008) are the synthesised theoretical discursive politeness framework adopted for analyzing the collected data Locher and Watts' (2005) abandon "any attempts to develop a universal, cross-culturally valid theory of politeness altogether" whereas Watts' (2003: 255) considers (im) politeness 'a part of the discursive social practice through which we create, reproduce and change our social worlds". There is no inherently polite or impolite linguistic behaviour (Watts, 2003 and Locher, 2006), rather what are generally used to index one polite communicative act and in one community, might be used to index a different one in another community. In other words, the linguistic utterances are open to various interpretations in particular situation.

The present study focuses on linguistic expressions used by speakers strategically to express relational work, negotiate face and express politeness in a fully contextualised situation which further reflects different socio-cultural values in both communities. Spencer-Oatey's $(2000,2008)$ concept of rapport management which accounted for my data well have been specifically utilized. Complaining could be a rapport sensitive communicative act without inevitably being viewed as intrinsically a face-threatening act as argued by Brown and Levinson (1987). This is because complaining may be expressed in a way that helps to establish, enhance or maintain smooth social relationships among people, rather than creating social problem. This means that relational work is achieved through creating and maintaining good social relationships. The present study also follows Terkourafi's approach/model of politeness in attempting to move beyond Brown and Levinson's work by concentrating on contextual variation. The account of politeness has been modeled around "frame-based" which is the participants' prior knowledge of contexts and the behaviour that can be politely applied in such settings (Terkourafi, 2005). In this model, politeness is equated with regularity - "politeness resides not in linguistic expressions themselves, but in the regularity of this co-occurrence [between linguistic expressions and a given context" (ibid: 248). Brown (2008) argues that the frame-based view offers an advantage in providing a mechanism whereby behaviour can be compared to societal norms without assuming or relying on pre-established prescriptive politeness norms such as in Brown and Levinson (1978) and Ide (1989), or rejecting them (Watts, 1989), rather it "acknowledges norms to the extent that these can be empirically observed" (Terkourafi, 2005: 247).

\subsection{Data analysis}

A new code scheme was devised in light of the previous well-known coding schemes (Olshtain and Weinbach, 1993; Trosborg, 1995, Rinnert and Nogami, 2006; Yian, 2008) in which every realisation pattern of the collected data fitted. Descriptive and statistical analyses were applied to the data. The frequencies and percentages of complaints strategies as part of the descriptive analysis were calculated in both languages using the Excel program which in turn explicates the respondents' preference of which complaints strategies to use according to which situation. The differences were analysed based on two dependent variables, namely the strategy's number and type. The analysis of the strategies' frequencies was conducted as follows: (a) the overall frequency of the strategies employed by Native Speakers of Arabic (NSsA) and Native Speakers of English (NSsE) in all situations (b) the overall total number of uses of each strategy in all the given situations. Furthermore, inferential statistics were conducted to roll out if there was a significant difference between the groups. In particular, T-test was used for conducting the comparison as there were one variable with two levels (culture; English and Jordanian). The significant differences were rolled out based on the means and standard deviations when the result is equal or less than $(\mathrm{p}<.05)$. The measure of significance employed in this study is $(\mathrm{p}<.05)$. In other words, if the $\mathrm{p}$-value is less than or equal to the alpha $(\mathrm{p}<.05)$, then the null hypothesis is rejected and we conclude that the result is statistically significant. 


\section{Results and discussion}

The analysis of the data revealed that the participants resorted to use a variety of expressions for conveying complaints. This means that complaining can be viewed as a communicative act set rather than a single speech act. The analysis was carried out in light of two main points: level of directness and amount of mitigation. The responses showed that complaints are conveyed both directly and indirectly.

The data analysed can be classified into the following taxonomy:

\section{Direct expression of complaints:}

1. Expression of annoyance about the offensive event and person or disapproval at the violation which does explicitly mention the complainable matter event.

English: "It won't be fair on the rest of us", "I'm trying studying for an exam but I can't concentrate". "I have to study another summer term because I trusted your judgment". "I'm not quite satisfied with it because I know I have put in the hours". "The way you have advertised this and its outcomes in reality are two completely different things", "Everything from the schedule to the organization of the practical elements on this trip has been an utter shame", "I didn't think that the organisation of the trip was very effective".

Arabic:

"You are careless". انت .غير مبالي"

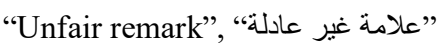

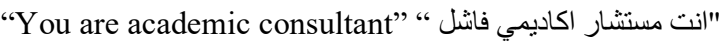

"this is cheating" " هذا غش"

\section{Direct threatening request to get the addressee to do something to redress the situation}

\section{English:}

"You have to pay for the repair". "Could you please turn your music down?" "can anything be done to make the necessary changes?", "Can you please get it done now", "Hey there's a queue here get to the back of it". "I don't care you have to repair it or buy me a new one", "please call the university and explain that you will get the money tomorrow.", "Ideally I would like a remark", "Please would you review my report as I thought that I had worked really hard and effectively for the company?".

Arabic:

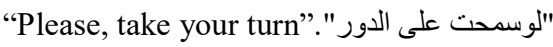

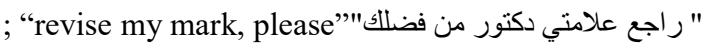

"إذا كان بالإمكان ألغي التقريرو اعمل على روية عملي بصدق"'"if it is possible, cancel the report and try to assess me honestly"

": "لست وحدك بالعالم, احترم نفسك و الاخرين'You are not alone in this world, respect yourself and others"

\section{Accusing, and warning which further implies hearer's responsibility for it and potential sanctions against the addressee}

English:

"The next time, don't expect me to consult you".

"I could lose my place if it is not paid on time", "This is your mistake". "You really put me in a serious trouble". "It is your fault"

Arabic:

"هذه الشركات غير محترمه"; “ these are un-respected companies”

"انت شخص غير مسوول; “you are an irresponsible person”

"خسرت مصاري على الفاضي"; "I have lost money”.

"Do not blame me if they withdraw my schedule" “" الاتلوموني ادا سحبو الجدول"

\section{Immediate threat is expressed as a complaint when the speaker chooses to openly attack the addressee}

\section{English:}

"If you don't finish the job today, I'll have to discuss it with the boss".

"I will take further undesired action", "Have you heard of the Trade Descriptions Act?", "I need this ASAP, my deadline is literally in half an hour".

Arabic:

"سأسحب الفصل كامل".I will withdraw the whole semester"

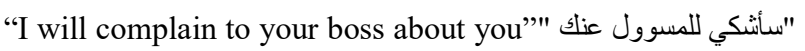

"I will not register the course and you are responsible" "ن اسجل الدورهو سوف تتحمل المسولية"

“" "I will hit you now”

“تركت المصنع اللكربك الان"، "I have left the factory for you”. 


\section{Indirect expression of complaints:}

\section{Opting out: Complete avoidance of mentioning the offensive action, event or person}

English:

"Nothing"

Arabic:

"I say nothing in such situation”."لا اقول شي في منل هذا الموقف"

"لاداعي لقول اي شيء"; "No need to say anything”"

\section{Prayers and wishes}

Arabic:

“Allah is sufficient”"حسبي الله ونعم الوكيل

“"May God forgive you” الله يسامحك" '

"Thanks to Allah for everything "الحمدله على كل حال"

" آمل ان تعقل وتبطل ولدنة" ; “ I wish you grow wise and stop childishness”

3. Advice

English:

"But in the future for other students, please note their circumstances",

"I advise you to become more organized in the future".

Arabic:

" يجب ان تحافظ دائما على ما لايخصك"”you should always keep others’ possessions" “

"انصحك بالاعتناء بترتيب الرحلة في المرات القادمة"; “ I do advise you to take care in organizing a trip next time”.

"لازمكم شخص خبير"; “ you are in need of an expert”"

\section{Irony}

“", you made your self more comfortable”.

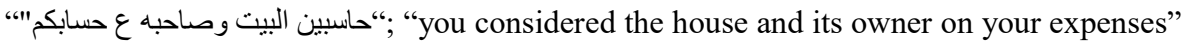

“مابحلها الا انت ياشاطر"; "no one except you, will solve it"

"we are very polite”"انتم مودبين جدا"

English:

Very nice friends!

Such a well-organized trip!

Arabic:

; "clever" فهيم"

"انت افضل شخص اعتمد عليه،" "you are the best person whom I could account on”.

\section{Rejoinder that does not show any disapproval, i.e. lessening the impact of the action}

English:

"Hi, I didn't mean to disturb you". "I'm sorry to be a bother", "I am sorry to trouble you".

Arabic:

" " "لاتهنم" " do not worry”.

“, “no problem for Sunday”, “ "للاحد ما في مشكلة".

"و ساستفيد منها في وقت اخر "I will benefit from it some other time",

"Do not worry, Sir"

"you may hate something but it is good”

"عادي فداكم ماصار شي"; “ it is normal, it is for your sake, nothing happened”. 


\section{Request for explanation and justification}

\section{English:}

"Would you be able to help me by perhaps explaining why?", "What did I do that was unsatisfactory?", "Why have you given me an unfair report?" "I would like to discuss the report you have written about me".

Arabic:

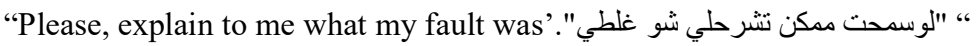

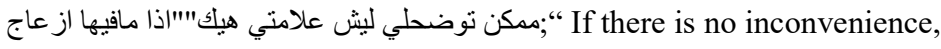

\section{Exclamation:}

English:

"Oh my God!”, "Gosh!”

Arabic:

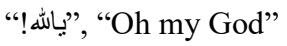

"Oh God, unbelievable!

It seems that performing the speech act of complaint involves a variety of semantic strategies which vary in their degree of severity on the addressee's face. Though the results revealed that the English natives used more strategies for expressing their complaints compared to their Jordanian counterparts, no statistically significant differences were found between both native groups in the number of the strategies used. Figure 1 shows the distributions of the overall complaints strategy use by both groups. It is evident that English natives employed more strategies (438 semantic expressions) whereas the Jordanian participants utilized (429 semantic expressions) strategies in all social situations. This could be referred to the Jordanians' higher use of the opting out strategy compared to the English which prevent them from using any other supporting strategies. The data agree with Al-Omari (2008) in that the use of opting out could be considered a polite strategy by Arabs to avoid an imposition and confrontations that may possibly disturb their harmony with others. This sounds a possibly logical reason for cutting their conversation in confrontational situations short by using no complaints expressions which may sound as an effective face-threatening speech act.

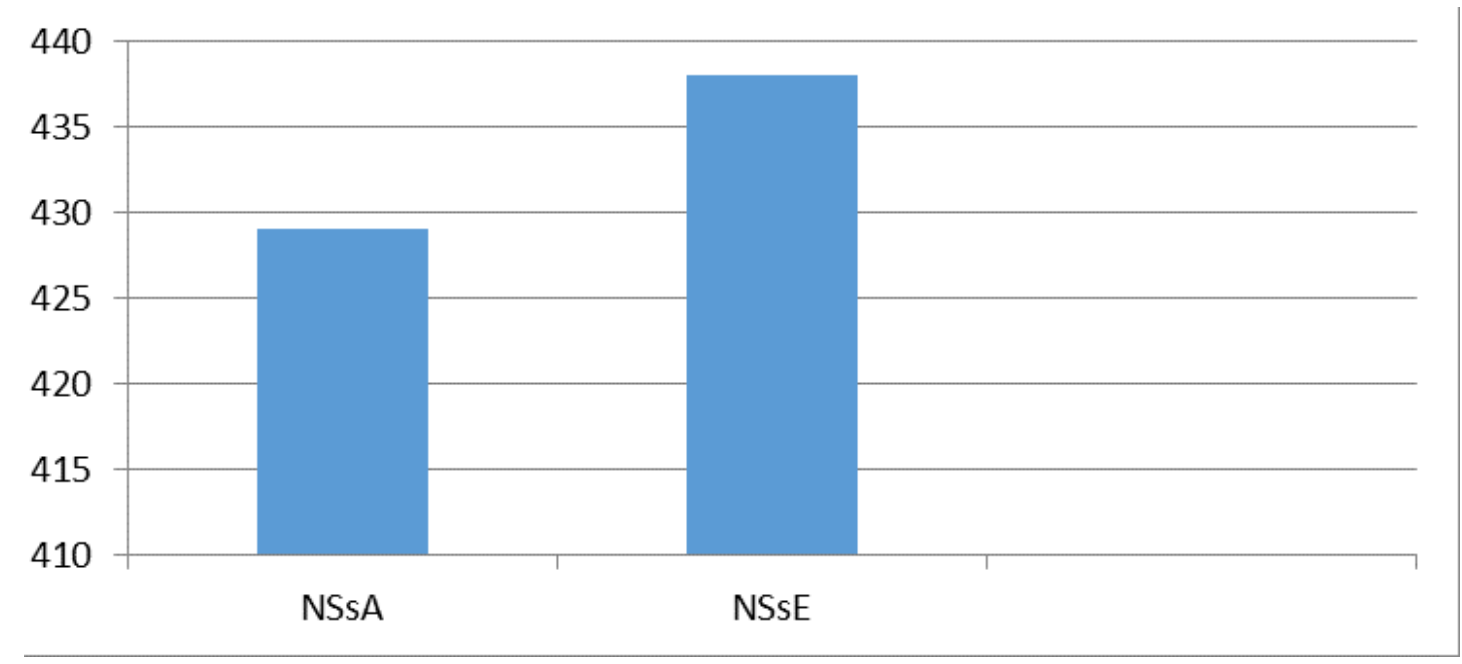

Figure 1. Overall frequency of all strategies for NSsA and NSsE in all situations

Table 1 shows that there are no significant differences in number of strategies used for expressing complaints by both native groups in all the social situations as p-value was found (.404). 
Table 1. T-test result of the differences in number of strategies used for expressing complaints by both native groups

\begin{tabular}{|c|c|c|c|c|c|c|c|c|c|}
\hline \multirow[t]{3}{*}{$\begin{array}{l}\text { No. of complaints } \\
\text { strategies }\end{array}$} & \multicolumn{2}{|c|}{$\begin{array}{l}\text { Levene's Test for } \\
\text { Equality of } \\
\text { Variances }\end{array}$} & \multicolumn{7}{|c|}{ t-test for Equality of Means } \\
\hline & \multirow[t]{2}{*}{$\mathrm{F}$} & \multirow[t]{2}{*}{ Sig. } & \multirow[t]{2}{*}{$\mathrm{t}$} & \multirow[t]{2}{*}{ df } & \multirow[t]{2}{*}{$\begin{array}{l}\text { Sig. (2- } \\
\text { tailed) }\end{array}$} & \multirow[t]{2}{*}{$\begin{array}{l}\text { Mean } \\
\text { Difference }\end{array}$} & \multirow[t]{2}{*}{$\begin{array}{l}\text { Std. Error } \\
\text { Difference }\end{array}$} & \multicolumn{2}{|c|}{$\begin{array}{l}95 \% \text { Confidence } \\
\text { Interval of the } \\
\text { Difference }\end{array}$} \\
\hline & & & & & & & & Lower & Upper \\
\hline $\begin{array}{l}\text { Equal variances } \\
\text { assumed }\end{array}$ & 2.914 & .092 & $-.840-$ & 68 & .404 & $-.25714-$ & .30600 & $-.86776-$ & .35348 \\
\hline $\begin{array}{l}\text { Equal variances } \\
\text { not assumed }\end{array}$ & & & $-.840-$ & 62.190 & .404 & $-.25714-$ & .30600 & $-.86880-$ & .35451 \\
\hline
\end{tabular}

With regard to the types of the complaining strategies both groups used, Figure 2 shows the tendency of the English participants to use more direct strategies than their Jordanian counterparts. They tended to use FTA expressions with explicit reference to the complainable matter and the person using the second person pronoun (i.e. you) mainly to instigate an action. The total number of strategies shows that the strategies of expressing general annoyance or disapproval (e.g. 'I think my grade was too low') and direct redress request (e.g. 'you have to pay it yourself'; "I would highly appreciate if you would reconsider my low grade' were the most employed strategies among all strategies. The least employed strategies by both groups were giving advice (e.g. "I see you have to be more organized in the coming trips") and irony ('a very amazing trip!'). This finding is not in congruence with Olshtain and Weinbach (1987: 203) who conclude that there is a "distinct bulging in the center and lessening of usage at the two extremes of the scale". They found that speakers favor the use of disapproval, complaints, and accusation, which are situated at the center of the directness scale, below the level of reproach and threat, which are positioned at the extreme ends of the scale. With regard to direct redress request, the analysed expressions can be classified, adopting Chen, et.al.(2011) and Blum-Kulka et.al. (1989) into hedged preformative, i.e. "Utterance whose illocutionary verb expressing the requisite intention is modified by modal verb", such as: "I would like you to revise my mark" and want statement "i.e. the utterances which express the speaker's desire for the hearer to carry out the act", such as: "I want you to respect yourself and others" (Blum-Kulka, et al. 1989: 18). It could be argued that hedged performative linguistic form sounds more polite as it reflects the value of solidarity politeness and politeness through facial expression. However, differences of how interlocutors perceive these two strategies whether as polite or impolite depend largely on the context including their social relationship.

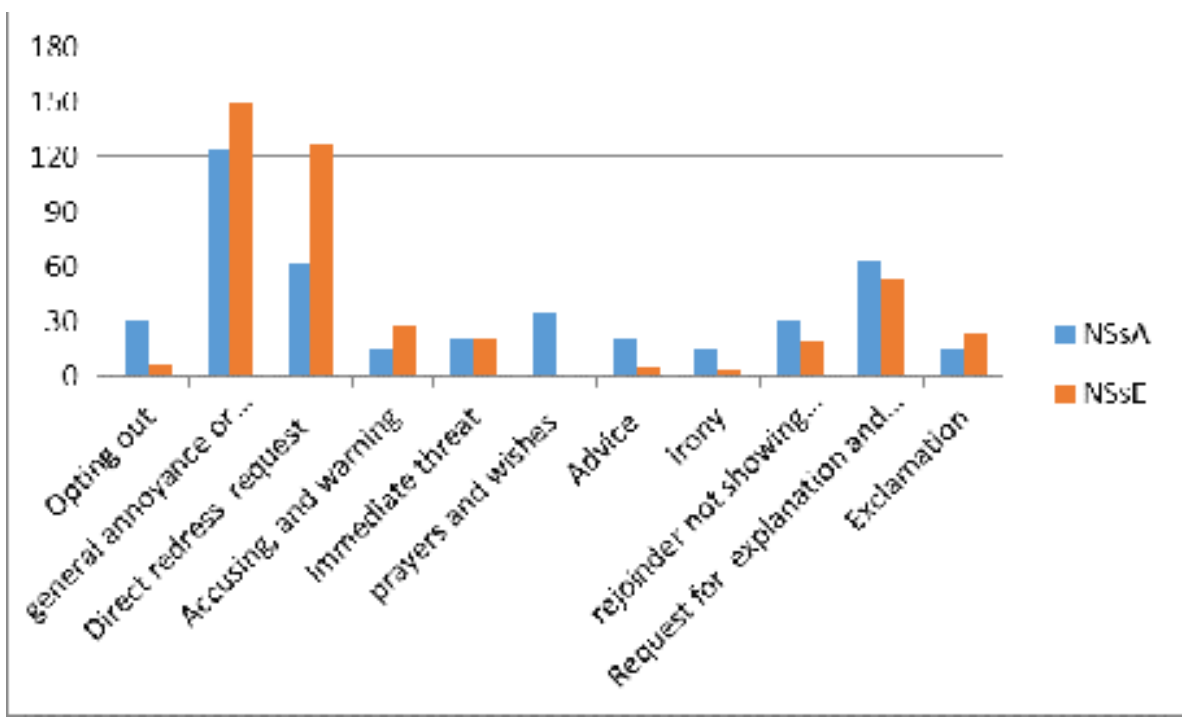

Figure 2. Complaining strategies

English employed accusing and warning (e.g. "I warn you to stop such bad behavior" as well as exclamation ('e.g. what have you done?!", ) more than Jordanians) e.g.(ماهذا؟)

In addition, the strategy of immediate threat was approximately used by both groups the same (e.g. "take care and get

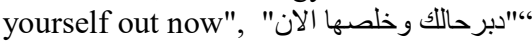

"; "I will not deal with you anymore”"I will reprimand you now”; “

This may imply the inclination of English to be more frank in conveying their complaints.

“I say nothing”),"لأقول شي On the other hand, Jordanians tend to opt out (e.g.

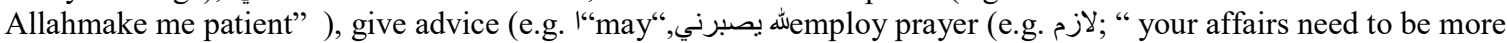
organized next time");"تنظمو ا اموركم اكثر بالمرات القادمة"

use a rejoinder that does not show explicit disapproval and dissatisfaction (e.g. 
"," "it is not important, many of such issues happen"; "كثير من هذه الامور تحدث مش مهر,"

"request for explanation and justification more than their English counterparts(e.g.

"; "explain to me how this happened”.فهمني كيف صار هيك"

This may indicate the tendency of Jordanians to be indirect in conveying their complaints. Table 2 shows significant differences in the use of certain semantic strategies for expressing complaints by both groups in all the social situations. Significant differences were found in employing the strategy of opting out $(\mathrm{p}<.000)$, expressing general annoyance and disapproval $(p<.029)$, direct request for repair $(p<.000)$, giving advice $(p<.000)$, irony $(p<.003)$, a rejoinder that does not show any disapproval $(\mathrm{p}<.004)$, in conveying their complaints. Both groups are statistically indistinguishable in their use of "accusing and warning", "immediate threat", "request for explanation" and "exclamation".

Table 2. T-test results of the significant differences in the use of semantic strategies for expressing complaints by both groups

\begin{tabular}{|c|c|c|c|c|c|c|c|c|c|c|}
\hline & & \multicolumn{2}{|c|}{$\begin{array}{c}\text { Levene's Test for } \\
\text { Equality of Variances }\end{array}$} & \multicolumn{7}{|c|}{-test for Equality of Means } \\
\hline & & \multirow[t]{2}{*}{$\mathrm{F}$} & \multirow[t]{2}{*}{ Sig. } & \multirow[t]{2}{*}{$\mathrm{t}$} & \multirow[t]{2}{*}{ df } & \multirow[t]{2}{*}{$\begin{array}{l}\text { Sig. (2- } \\
\text { tailed) }\end{array}$} & \multirow[t]{2}{*}{$\begin{array}{c}\text { Mean } \\
\text { Difference }\end{array}$} & \multirow[t]{2}{*}{$\begin{array}{l}\text { Std. Error } \\
\text { Difference }\end{array}$} & \multicolumn{2}{|c|}{$\begin{array}{c}95 \% \text { Confidence Interval of } \\
\text { the Difference }\end{array}$} \\
\hline & & & & & & & & & Lower & Upper \\
\hline \multirow[t]{4}{*}{ Opting out } & Equal variances & 1.957 & .166 & 6.056 & 68 & .000 & .68571 & .11323 & .45977 & .91166 \\
\hline & assumed & & & & & & & & & \\
\hline & Equal variances & & & 6.056 & 60.643 & .000 & .68571 & .11323 & .45927 & .91216 \\
\hline & not assumed & & & & & & & & & \\
\hline \multirow[t]{4}{*}{ annoyan } & Equal variances & 3.907 & .052 & $-2.228-$ & 68 & .029 & $-.57143-$ & .25649 & $-1.08324-$ & $-.05961-$ \\
\hline & assumed & & & & & & & & & \\
\hline & Equal variances & & & $-2.228-$ & 65.273 & .029 & $-.57143-$ & .25649 & $-1.08363-$ & $-.05923-$ \\
\hline & not assumed & & & & & & & & & \\
\hline \multirow[t]{4}{*}{ request } & Equal variances & 55.277 & .000 & $-7.869-$ & 68 & .000 & $-1.88571-$ & .23965 & $-2.36392-$ & $-1.40750-$ \\
\hline & assumed & & & & & & & & & \\
\hline & Equal variances & & & $-7.869-$ & 48.807 & .000 & $-1.88571-$ & .23965 & $-2.36735-$ & $-1.40408-$ \\
\hline & not assumed & & & & & & & & & \\
\hline \multirow[t]{4}{*}{ accusing } & Equal variances & .922 & .340 & $-.488-$ & 68 & .627 & $-.11429-$ & .23397 & $-.58117-$ & .35259 \\
\hline & assumed & & & & & & & & & \\
\hline & Equal variances & & & $-.488-$ & 67.932 & .627 & $-.11429-$ & .23397 & $-.58117-$ & .35260 \\
\hline & not assumed & & & & & & & & & \\
\hline \multirow[t]{4}{*}{ threat } & Equal variances & .000 & 1.000 & .000 & 68 & 1.000 & .00000 & .11882 & $-.23710-$ & .23710 \\
\hline & assumed & & & & & & & & & \\
\hline & Equal variances & & & .000 & 68.000 & 1.000 & .00000 & .11882 & $-.23710-$ & .23710 \\
\hline & not assumed & & & & & & & & & \\
\hline \multirow[t]{4}{*}{ advice } & Equal variances & 30.222 & .000 & 4.123 & 68 & .000 & .42857 & .10394 & .22115 & .63599 \\
\hline & assumed & & & & & & & & & \\
\hline & Equal variances & & & 4.123 & 61.200 & .000 & .42857 & .10394 & .22074 & .63641 \\
\hline & not assumed & & & & & & & & & \\
\hline \multirow[t]{4}{*}{ irony } & Equal variances & 43.033 & .000 & 3.115 & 68 & .003 & .31429 & .10090 & .11295 & .51562 \\
\hline & assumed & & & & & & & & & \\
\hline & Equal variances & & & 3.115 & 58.005 & .003 & .31429 & .10090 & .11232 & .51625 \\
\hline & not assumed & & & & & & & & & \\
\hline \multirow[t]{4}{*}{ nodisap } & Equal variances & 33.428 & .000 & 3.010 & 68 & .004 & .31429 & .10440 & .10595 & .52262 \\
\hline & assumed & & & & & & & & & \\
\hline & Equal variances & & & 3.010 & 60.983 & .004 & .31429 & .10440 & .10551 & .52306 \\
\hline & not assumed & & & & & & & & & \\
\hline \multirow[t]{4}{*}{ explain } & Equal variances & 46.878 & .000 & 1.090 & 68 & .280 & .25714 & .23601 & $-.21381-$ & .72810 \\
\hline & assumed & & & & & & & & & \\
\hline & Equal variances & & & 1.090 & 47.803 & .281 & .25714 & .23601 & $-.21744-$ & .73173 \\
\hline & not assumed & & & & & & & & & \\
\hline \multirow[t]{4}{*}{ exclam } & Equal variances & 38.017 & .000 & $-1.108-$ & 68 & .272 & $-.20000-$ & .18044 & $-.56005-$ & .16005 \\
\hline & assumed & & & & & & & & & \\
\hline & Equal variances & & & $-1.108-$ & 51.875 & .273 & $-.20000-$ & .18044 & $-.56209-$ & .16209 \\
\hline & not assumed & & & & & & & & & \\
\hline
\end{tabular}

The findings suggest that cultural variation in conveying complaints is due to the high degree of sensitivity to the interplay of several social and contextual variables. Such differences were analyzed considering the variation of the choice of the type of complaint strategy in light of an interplay between some social and contextual factors. In other 
words, the data revealed that the English participants were more direct in most of the situations than their Jordanian counterparts who resort more to opting out strategy, giving advice and using a rejoinder that does not show any disapproval toward in-group interlocutors (i.e. family, friends etc.) and out-group interlocutors of a high social status (i.e. complaining to a professor)and more direct strategies when to complaining to out-group interlocutors of low social familiarity and low social status (i.e. stranger, administrator). This could be ascribed to the strong social ties between the Jordanian society members (i.e. brothers and sisters) and the significance of the social status being described as a stratified society (Al-Khatib, 2001). The high use of prayers by Jordanian participants compared to their British counterparts could be ascribed to the impact of religion on language use (i.e. the strong belief in Allah).

The data were also analyzed in light of amount of mitigation. It was found that Jordanians used more opening formulae such as greeting "AsslamoAlycom; Hello" besides the address terms such as "Sir, dear, brother" and establishing and explaining the context (e.g. لقد طلب عمل سبعة نسخ من مشروع يوم الاثثنين"; "I placed an order for 7 copies of my project on Monday" compared to their British counterparts who used more softeners and mitigations such as excusing self for imposition (e.g. Excuse me for interrupting you, please, I wonder...., you could..., I think you should'. The use of lots of mitigations and expressions of complaints particularly the indirect expressions (i.e. opting out, rejoinder that lessens the impact of the action, giving advice) could very often have been caused by their desire to be cautious considering the various social and contextual variables. Thus, it could be argued that expressing mitigated complaints may not be viewed as intrinsically face-threatening acts rather it may be claimed that expressing complaints should be viewed as a way of establishing and sustaining social relationships as opposed to Brown and Levinson's (1987) claim. They may function as a kind of phatic communion that helps promoting solidarity between the interlocutors (i.e. complainer and complainee). Thus, the data is in line Olshtain and Weinbach (1993) and Trosborg (1995) who found that making a complaint serves two major purposes; besides expressing negative attitudes including frustration or disapproval toward the bad action executed by the complainee, it also helps the complainee to refrain from the bad behaviours or to reimburse for the damages he/she has caused. This could explain the use of both direct and indirect expressions of complaints simultaneously sometimes in the same situations. The order in which the components of the expression of complaints are performed could also reveal some variation and significant implications for future research.

The findings also support Bardovi-Harlig and Griffin (2005) in asserting that although people from cultures and speaking different languages may employ somehow similar types of strategies for realizing the communicative act of complaining, what counts as appropriate expression of complaints in certain situation and in specific speech community varies from culture to culture. The finding also lends support to Yu's results that the strategy preferences of the speakers are subject to "a culture's ethos and its own specific way of speaking" (2003: 1704). This is because cultural values and believes are often reflected in the content represented by a certain strategy. Based on the data, it could be argued that through using more direct complaints expressions, the English participants asserts the notion of social equality where social power has less impact. In contrast, the stress of the Jordanian participants on the use of more indirect various complaints expressions depending on the social status of the interlocutor could indicate that the social power variable may be an overriding influence in Jordanian society.

The results may point to the difficulties that nonnative speakers may face when complaining about an issue to naive speakers. In other words, speakers of different cultures are observed to unintentionally bring into communications some culture-associated assumptions, norms and pragmatic rules (i.e. pragmatic transfer), which is probably the source of unintended impressions, which in turn may lead to un-favored results (i.e. communication misjudgment, cultural conflicts; pragmatic failure).Accordingly, the findings of this research study may serve as guidance for teaching English as a second language to British English and Jordanian Arabic speakers. It also suggests that it is necessary for language teachers and learners to be fully aware of the cultural differences between English and Jordanian's expression of complaints.

\section{Conclusion and recommendation}

The study revealed cross-cultural difference in the types of expressions used for conveying complaints by both British English and Jordanian Arabic speakers. Whereas British English tended to use more expressions of general annoyance and disapproval, request for direct repair, as well as accusation and threat, the use of opting out, prayers and advice were the characteristics of the Jordanian Arabic speakers' expression of complaints. The differences were analyzed considering the interplay between cultural, social and contextual variables.

In order to verify and generalize these findings, this research can be replicated by conducting a study on a large sample and some other different social situations. The data of this study was based only on written elicited data i.e. it only represented what the participants would say in a particular situation. Thus, more authentic contexts -based studies are needed to make more certain conclusions about the communication of complaint in Jordan and England. More studies are needed to investigate the impact of some other social variables (i.e. age, gender and socio-economic backgrounds of interlocutors). Pragmatic transfer, as it applies to complaining by Jordanian English learners, needs to be investigated further.

\section{References}

Al-Ali, M. and Alawneh, R. (2010). Linguistic mitigating devices in American and Jordanian students' requests. Intercultural Pragmatics, 7(2), 311-339. 
Al-Khatib, M. A. (2006). The pragmatics of invitation making and acceptance in Jordanian society. Journal of Language and Linguistics, 5(2), 272-294.

Al-Khawaldeh, N. N. (2014). Politeness in the linguistic expression of gratitude in Jordan and England: A comparative cross-cultural study. Unpublished PhD thesis. England: University of Bedfordshire.

Al-Khawaldeh, N. N., \& Žegarac, V. (2013). Cross-cultural variation of politeness orientation \& speech act perception. International Journal of Applied Linguistics and English Literature, 2(3), 231-239.

Al-Omari, J. (2008). Understanding Arab culture: a practical cross-cultural guide to working in the Arab world. Oxford: How to Books Ltd.

Bardovi-Harlig, K., \& Griffin, R. (2005). L2 pragmatic awareness: Evidence from the ESL classroom. System, 33(3), 401-415.

Blum-Kulka, S., House, J. \& Kasper., G. (1989). Investigating cross-cultural pragmatics: An introductory overview. In: Blum-Kulka, S. House, J. \& Kasper., G. (eds.), Cross-cultural pragmatics: Requests and apologies, 1-36. Norwood, New Jersey: Ablex.

Brown, P., \& Levinson, S. C. (1987). Politeness: Some universals in language usage. Cambridge University Press.

Chen, Y. S., Chen, C. Y. D., \& Chang, M. H. (2011). American and Chinese complaints: Strategy use from a crosscultural perspective. Intercultural Pragmatics 8(2), 253-275

Clyne, M. (1994). Intercultural communication at work: Cultural values in discourse. Cambridge University Press: Cambridge.

Crawshaw, R., Culpeper, J., \& Harrison, J. (2010). Wanting to be wanted: a comparative study of incidence and severity in indirect complaint on the part of French and English language teaching assistants. Journal of French Language Studies, 20(01), 75-87.

Hussein, J. Q. \& Al-Mofti, K. (2014). The speech act of complaint: A contrastive study of Iraqi and Chinese EFL learners of English. Anbar University Journal of Language and Literature, 13, 65-81

Kurdghelashvili, T. (2015). Speech acts and politeness strategies in an EFL classroom in Georgia. International Journal of Social, Behavioral, Educational, Economic, Business and Industrial Engineering, 9(1), 306-309

Mayouf, H. H. (2013). The speech act of complaint as realized by Iraqi Arabic speakers, Journal of Human Sciences, 1(14): $362-38$

Meier, A. J. (2010). Culture and its effect on speech act performance. Speech act performance: Theoretical, empirical and methodological issues, 75-90. Amsterdam: John Benjamins.

Muhammed, B. A. (2012). A contrastive pragma-sociolinguistic study of etiquette teachings in English Christian and Arabic Islamic texts. Unpublished PhD thesis. University of Baghdad, Baghdad.

Murphy, J. (2015). Revisiting the apology as a speech act: The case of parliamentary apologies. Journal of Language and Politics, 14(2), 175-204.

Newell, S., \& Stutman, R. (1989/1990). Negotiating confrontation: The problematic nature of initiation and response. Research on Language and Social Interaction, 23, 162-132

Olshtain, E., \& Weinbach, L. (1987). Complaints-A study of speech act behavior among native and nonnative speakers of Hebrew. Tel Aviv University.

Olshtain, E., \& Weinbach, L. (1993). Interlanguage features of the speech act of complaining. Interlanguage pragmatics, 108, 22.

Rhurakvit, M. (2011).Complaints in Thai and English: An interlanguage pragmatic study. Unpublished PhD thesis. United Kingdom: University of London.

Spencer-Oatey, H. (2005). (Im)politeness, face and perceptions of rapport: Unpackaging their bases and interrelationships. Journal of Politeness research: Language, Behaviour, Culture, 1(1), 95-119.

Spencer-Oatey, H. (2003). Managing rapport in intercultural business interactions: a comparison of two Chinese-British welcome meetings. Journal of Intercultural Studies, 24(1), 33-46.

Sukyadi, D. and Ayu, D., (2011). Complaining in EFL learners: differences of realizations between men and women. Parole, 2(1), 1-25.

Tanck, S. (2002). Speech act sets of refusal and complaint: A comparison of native and non-native English speakers' production. Studies in Second Language Acquisition, 13, 65-81

Yarahmadi. A and Fathi, S. (2015). A cross cultural study on Iranian EFL students' pragmatic transfer. Social and Behavioral Sciences, 192, 498 - 505.

Yu, M. (2003). On the universality of face: Evidence from Chinese compliment response behavior. Journal of Pragmatics 35, 1679-1710. 